By LYNDAL SWOFFORD

\title{
Mental Hygiene and the College Library ${ }^{1}$
}

$\mathrm{T}$

HE TYPICAL LIBRARY WORKER does not exist, but a composite picture of a mythical college librarian may help one to understand the general frustrating environment peculiar to the profession. This mythical creature is an unmarried woman past thirty. Experience has shown her that only a few women of her age in her profession have an opportunity for marriage, even though no obvious personality defects or environmental factors, such as regulations barring married women from the school system, may block the way.

Her salary will vary with the region in which she lives but, considering that she is usually supporting two dependents, ${ }^{2}$ she does not find it adequate for food, clothing, shelter, medical attention, and recreation for herself and her dependents, plus the study and travel she has been taught to believe are necessary for personal and professional growth. She is likely to be in debt for her extra year of library training or for the illness of some member of the family. She may feel a sense of injustice because her salary is not equivalent to that paid men of like training and experience. In some situations, if she marries she will lose her job, while a man of like professional status will receive a bonus for dependents. The fact that her own dependents are not "chosen" is of no concern to those who appropriate money for her salary. How-

\footnotetext{
1 Portion of a paper presented at the meeting of the Libraries of Teacher-Training Institutions Section, American Library Association Conference, Buffalo, June $21,1946$.

"Smith. H. L. "Social Status of the Teacher." Review of Educational Research $18: 258-65$, June 1940 .
}

ever, unless she has strongly developed maternal tendencies so that she gets sufficient satisfaction out of protecting and providing for the happiness of these dependents, she is likely to feel frustrated by the need to carry on another's unfinished business instead of devoting her time and income to progress in her own chosen direction.

The college librarian's social status, like that of other members of the school personnel, varies inversely with the prosperity of the community. ${ }^{3}$ In communities of little wealth, she is at the top of the social strata; in those of considerable. wealth, she may find that she is considered among the upper or special servant class, the group in which are found governesses, nurses, tutors, etc. Even in the average community, where she is accepted as a member of the professional class, she may be hedged about by many puritanical restrictions not placed upon other professional persons. In most cases, insecurity of tenure makes it impossible for her to do anything except conform to these restrictions. In some conservative communities, members of the college personnel may not smoke, dance, or drink a cocktail in public. The librarian may not wish to engage in any of these unimportant social gestures, but she resents "class restrictions." An unmarried woman may not live in an apartment alone or share a separate house with another woman without being looked upon with suspicion. She may not associate with men on the same social basis as other business and professional women in the com-

3 Ibid., p. 263. 
munity. She is expected to make herself over from a human being into a professional automaton and, if she succeeds, she is considered "queer" or "different" or "highbrow."

The difficulty of maintaining satisfactory living conditions is complicated, not only by community restrictions, but also by housing conditions, impermanency of position, and inadequate salary. While the college librarian's salary places her at the bottom of the professional class, or at the top of skilled laborers or artisans, it usually does not allow her to live up to the standards which society expects of her and which she has been taught to consider as "the right way" for educated people to live.

This "typical" college librarian frequently finds that her opportunities for recreational activities are limited by the small amount of time she has free from scheduled duties, committee work, participation in community service clubs, and the like, as well as by a salary which does not permit her to follow her tastes in the matter of recreation. If she finds no opportunity for creative expression in her work, she will have a double need for some type of recreational activity which brings release from emotional tension.

If, in addition to restrictions and insecurity due to community attitudes, lack of tenure and retirement plans, and an inadequate salary, the library assistant must work under a cold and impersonal administrator who manipulates his staff like chessmen to his own advantage, then indeed is the situation difficult. Both autocratic administration, which simply commands, and weak administration, which is never able to give advice, back up an undertaking, or promote the advancement of the assistant, contribute to the general unhappiness and dissatisfaction of the staff.

This composite picture, based on information assembled from various studies of the school personnel, presents a situation in which there are undoubtedly many factors frustrating to the normal individual. In regard to most of these conditions, there can be no immediate improvement, and changes will only come slowly through group action and long-time planning. Many of these factors are related to the general economic situation, social-class attitudes, and type of education now available to those who select library work as a vocation. What to do to make the situation more tolerable today in one's own library is the problem of the library administrator.

A careful study of these attributed causes of maladjustment suggests the possibility that an individual of mature personality, while working with others of his group toward improvement in salary, social status, etc., could find some means of making an adjustment to the present situation. For example, the matter of social status in the community or on the faculty depends, to some extent, on knowing how to establish personal-social relationships, how to find groups in which one is accepted as a congenial person or as one who has something to contribute. The conflict within the individual who feels that he lacks social status may be due to the fact that he feels left out of a particular social group with more money or different tastes rather than the fact that he can find no congenial companions in the community. An objective attitude toward the self rather than an emotional attitude, a set of values which promotes self-confidence, and absorbing personal interests, might resolve the conflict over social status.

\section{Library Administrator's Part}

It is not likely that the library administrator, who is untrained in the field of mental hygiene, can help maladjusted persons uncover deep-seated emotional conflicts and 
change modes of behavior that have been built into the personality over a period of thirty years. Such an attempt might prove to be dangerous experimentation. However, it would be wise for anyone who must take responsibility for selecting and directing the work of others to prepare for such work by taking one or more courses in mental hygiene. Failing this opportunity, the administrator may find out what he can by reading, observing, and reflecting. Obviously, taking a course or reading a book will not prepare one to diagnose and prescribe for serious mental maladjustments, but some knowledge of the basic needs of human beings and ways of adjustment to these needs, plus the will to help those for whom one is responsible, to be as happy and efficient as possible, should enable the library administrator to reduce the amount of maladjustment among the staff. For the most part, the library administrator's role in mental hygiene will be that of protecting and promoting mental health through control of the library environment.

The foregoing search for factors contributing to maladjustment seems to indicate that the most important problems center around the basic personality needs. Personality is many-faceted, and numerous lists of needs have been suggested. Gates has provided a list which may be used profitably in the preliminary planning of a mental hygiene program.

\section{Basic Personality Needs}

I. The need for affection-to live in a relationship of reciprocated warm regard for one or more individuals

2. The need for belonging-to feel that one is an accepted, valued member of a group

3. The need for independence-to be able to make one's own decisions and carry out one's own ideas

4. The need for social approval-to feel that one's personality and one's actions are respected and admired by others
5. The need for maintaining self-esteemto feel that one's conduct comes up to certain inner standards and thus merits one's own respect.

\section{Suggestions for a Positive Program}

To formulate a positive program of mental hygiene, considering that every individual's needs and modes of behavior are unique, seems difficult. However, Hill, McKinney, ${ }^{5}$ Shaffer ${ }^{6}$ and others have listed general principles of positive mental hygiene which can be adapted to the library situation.

The foregoing study of the probable causes of maladjustment among members of the school personnel suggest the following objectives as a basis for planning a program of mental hygiene in the library:

A. General Objectives of the Mental Hygiene Program in the Library

I. To provide an environment as free as possible from frustrating situations

2. To help the individual find ways of adjustment satisfactory to himself and acceptable to society

3. To promote the attainment, on the part of each staff member, of a mature personality characterized by:

a. Chosen goals which represent an extension of the self

b. Self-objectification

c. A unifying philosophy of life.

B. Specific Objectives and Methods of Procedure

I. To improve selection

a. Selection of applicants by the library school before training is begun, to screen out those personalities not likely to adjust to library situations

b. Selection by the library administrator:

(I) For the protection of the staff from a new personality who may in-

1 Hill, G. E. "Mental Hygiene of the Teacher." Educational Administration and Supervision 23:512, October 1937.

${ }_{5}$ McKinney, Fred. Psychology of Personal Adjust. ment: Students' Introduction to Mental Hygiene. New York, Wiley, r94I, p. 548-49.

6 Shaffer, L. F. The Psychology of Adjustment. Boston, Houghton, 1936, p. 535-40. 
troduce discord and unhappiness

(2) For the protection of the applicant, to prevent him from taking a position for which he may not be suited

c. Good selection would depend on:

(I) Assembling all possible information about the applicant as to personality traits, special abilities, attitudes, etc.

(2) A personal interview which will give the administrator an opportunity to find out how the applicant is likely to impress others. At this interview details about the job, the salary, opportunity for advancement, etc., should be fully explained so the applicant, if employed, will later have no reason for dissatisfaction about some matter of which he was not fully informed

(3) Careful analysis of all information assembled, in light of the conditions existing in the library

2. To remove all causes, insofar as possible, of insecurity, anxiety, and irritation due to physical conditions in the work environment

a. Try to find out from each assistant the sources of annoyance which may hinder the efficiency of his work by increasing emotional tension. Some persons, for example, cannot work well if crowded too close to others, if the light falls on the "wrong" side of the desk, if constantly associated with another who has irritating mannerisms, etc. Change in location of the work, or in routine, may be all that is needed

b. Maintain a flexible schedule that will allow each assistant to arrange for some freedom as to the hours when he may be off duty. Opportunity to attend to unexpected business, a club meeting, or even an occasional game of golf during work hours will yield large returns in reduced emotional tension. Work should be measured by the total output rather than by the number of minutes worked

c. Vary work to prevent monotony and fatigue. See that each assistant has a schedule that permits change to different types of work at intervals, if such change is desired. For example, a cataloger may do a better job of cataloging if he can spend an hour or two a day working with people rather than books. Whether such a plan is profitable or not depends on the personality of the cataloger

d. See that each assistant has complete and detailed information as to his position in the library, salary, tenure, hours of work, objectives, procedures, etc. Have a definite understanding so there will be no feeling of confusion, insecurity, and injustice

3. To promote the maintenance of good physical health. (The library administrator should be close enough to the staff to be aware of evidences of physical ill health which might be the cause of maladjustment.)

a. Suggest a physical check-up when it seems necessary

b. Try to arrange schedules to allow for necessary outdoor recreation

c. Arrange work so that sick leave can be allowed when necessary, without causing the library worker worry about loss of time

4. To help members of the library staff find means of recognizing and solving their own emotional and personal problems

a. If possible, require a course in mental hygiene, suggesting that the purpose is to help the staff understand how to work most effectively with their colleagues and with the library clientele

b. See that those who need special attention, beyond the ability of the layman, have an opportunity to get help from those trained in the field of mental hygiene

5. To provide for a sense of accomplishment and success

a. Find the work for which each assistant is best equipped so that he does not feel required to accomplish something beyond his capacity

b. Make assignments of jobs and help the assistant organize his routine in such a way that he does not feel always overloaded

c. Do not fail to give praise for successful accomplishment. Tell the assistant of any complimentary remark concerning his work which may have come to the attention of the administrator

6. To provide for the need to give and receive affection 
a. Demonstrate to each assistant that you are interested in his personal welfare and value him as a friend and co-worker. Know his home life, his special interests, his hobbies. Let him know of your efforts in recommending promotions and salary increases when they are justly due

b. Promote friendly feeling and a sense of mutual interdependence between members of the staff. Make all members feel that their contributions are of equal worth, though in different fields. Avoid carefully any action that might be interpreted as favoritism

c. Organize the work so that each assistant will have the opportunity for pleasant and helpful relationships with students and faculty members. Give each an opportunity to offer some personal service in a way that will be appreciated as his own contribution, not the work of the group

d. Encourage opportunities for friendly relationships with people in the community. Try to bring members of the staff into contact with others of like interests

7. To promote the feeling of belonging, of recognition, of group status

a. Encourage staff members to serve on committees to which they may make a special contribution, the curriculum committee or a committee which needs the help of a person skilled in making bibliographies, for example

b. Encourage staff members to take part in community service clubs and organizations of all types. Allow some time to do the extra work thus involved

c. Try to interest each staff member in some group work for leadership in which he is specially fitted

d. Watch for opportunities which will permit staff members to receive school and community recognition for successful accomplishments

e. Encourage membership in local, state, and national professional groups which are working for the improvement of conditions affecting library work: increased salaries, tenure and retirement plans, community restrictions, etc. While no immediate change may be possible, the sense of belonging to powerful groups working for one's betterment promotes a hopeful attitude

8. To provide opportunity for independent, creative work

a. Encourage suggestions which assistants may present for routines and special projects connected with their work

b. Do not supervise details, but let each assistant plan his work in his own way insofar as he is capable

c. See that the individual receives credit in his own name for any noteworthy project instead of the credit being awarded to the group as a whole or to the administrator

9. To encourage absorbing leisure-time interests. (Leisure-time interests provide not only recreation and change from routine duties but also means of compensating for thwarted needs.). Types of activities of special value are:

a. Creative activities and hobbies of all types, especially those which involve manual skills

b. Outdoor recreations and sports which bring about a sense of physical well-being and help one to forget everyday routines

c. Esthetic interests, music, art, drama, etc., which one may enjoy with people of similar tastes

d. Social group recreations which may be carried on in the play spirit: dancing, parties, etc.

e. Travel which will broaden interests and promote an understanding of conditions in other communities

f. Study courses which are not directly connected with one's work but which broaden one's viewpoint and widen one's interests

I0. To encourage a hopeful outlook for the future

a. Help the individual to see when he is making progress

b. Make him feel that you will do all in your power to promote his professional growth

c. Encourage plans for future study, travel, etc.

d. Bring to the attention of the staff any general improvement in the status of college libraries 
11. To set up democratic administrative procedures

a. Create an atmosphere of cooperative participation on the part of all members of the staff

b. Let the members of the staff understand that, while the library administrator is the staff member directly responsible to school authorities, all members have a part in planning and policy making

c. Let the members of the staff understand that they are colleagues, not employees

d. Work out all routines with those directly concerned. Avoid making changes or adding duties without consulting those concerned.

As the tempo of our lives is accelerated by the speed of the Atomic Age, emotional pressures will increase. The techniques pointed out to us by the science of mental hygiene for reducing the ever increasing stresses and strains upon human relations provide us with safety valves. These devices for living and working together happily and efficiently are not new to any of us. Nevertheless, in the absence of verified study of actual conditions, observation seems to indicate that many college library administrators have not given enough attention to the application of the principles of mental hygiene as a factor in promoting congenial cooperation among members of the library staff and friendly, understanding service to faculty and students. In studying the situation in his own library and working out a program to promote and protect the mental health of the staff, the library administrator may make a small but important contribution to our only hope for a future in the Atomic Age, i.e., the advance of democracy. In the words of Frank, "Whatever fosters and promotes mental health will guard and advance democracy." 7

\section{Summary}

I. Since librarians are largely drawn from the same sources as teachers and other members of the school personnel and since they work under similar conditions, studies of the school personnel seem to indicate that the library administrator is likely to find some maladjusted persons on the library staff. These maladjusted persons may act as "chemical irritants" in their effect on co-workers and library clientele.

2. The chief causes of maladjustment of members of the school personnel seem to be: (a) emotional immaturity, and (b) environmental conditions.

3. The library administrator, as a layman in the field of mental hygiene, will be able to do little about deep, underlying emotional conflicts, but he may be able to do much to alleviate conditions through control of environmental factors.

4. A positive program of mental hygiene in the library would attempt: (a) to remove as many as possible of the causes of insecurity and irritation, (b) to create an atmosphere of successful achievement and hope for the future, (c) to promote the physical and mental well-being of the individual.

\footnotetext{
"See "The Reorientation of Education to the Promotion of Mental Hygiene" by Lawrence K. Frank, in Mental Health (Publication of the American Association for the Advancement of Science, v. 9), edited by F. R. Moulton and P. O. Komora, Lancaster, Pa., The Science Press, 1939, p. 284-85.
} 